\title{
An Approach to Tentative Reference Levels Setting for Nanoparticles in the Workroom Air Based on Comparing Their Toxicity with That of Their Micrometric Counterparts: A Case Study of Iron Oxide $\mathrm{Fe}_{3} \mathrm{O}_{4}$
}

\author{
Boris A. Katsnelson, Larisa I. Privalova, Sergey V. Kuzmin, Vladimir B. Gurvich, \\ Marina P. Sutunkova, Ekaterina P. Kireyeva, and Ilzira A. Minigalieva \\ Department of Toxicology and Biological Prophylaxis, Medical Research Center for Prophylaxis Health Protection in Industrial Workers, \\ 30 Popov Street, Ekaterinburg 620014, Russia
}

Correspondence should be addressed to Boris A. Katsnelson, bkaznelson@etel.ru

Received 24 April 2012; Accepted 7 June 2012

Academic Editors: Q. Chen and J. Ding

Copyright (C) 2012 Boris A. Katsnelson et al. This is an open access article distributed under the Creative Commons Attribution License, which permits unrestricted use, distribution, and reproduction in any medium, provided the original work is properly cited.

\begin{abstract}
We overview the state of the art in the field of safe exposure levels setting for nanomaterials together with the previously published results of our experimental investigations characterizing comparative toxicity of the iron oxide $\mathrm{Fe}_{3} \mathrm{O}_{4}$ (magnetite) in the form of microparticles and nanoparticles of different size and comparative activity of the defensive alveolar phagocytosis response to their pulmonary deposition. An approach to the substantiation of acceptable workplace exposure limits of metallic nanoparticles is discussed and, specifically, the tentative reference level for magnetite nanoparticles is recommended.
\end{abstract}

\section{Introduction}

The development of nanotechnologies has led to the emergence of a lot of materials containing nanoscale particles. By convention, a particle is defined as being in the nanoscale range if it has at least one linear dimension not exceeding $100 \mathrm{~nm}$. Nanoparticles (NPs) of various materials find wide application in different industries, in medicine, and in science. In particular, magnetite $\left(\mathrm{Fe}_{3} \mathrm{O}_{4}\right)$ NPs are increasingly often used in medicine and biology as selective carriers of drugs to organs, as markers controlled by an external magnetic field, as cancer cell killers (thanks to local hyperthermia caused by the heating of these NPs in a external variable magnetic field), as a contrast material in magnetic resonance tomography, and so forth. Looking for advance in general nanotoxicology, uncoated engineered NPs of any iron oxide present an interesting research object because such research brings us nearer to the answer of the important question of whether or not a material which is extremely low toxic both in bulk and in the micrometer particle size range may become so toxic in the nanostate, that it may present a serious hazard to human health in the course of its production and use. A good evidence of the rather low toxicity of usual (not nano-scale) iron oxides is that they are allowed by the Joint Expert Committee on Food Additives (JECFA) for use as colouring agents due to their being practically innocuous at a systematic daily intake of up to $0.5 \mathrm{mg} / \mathrm{kg}$.

Theoretical grounds for expecting a sharp increase in the toxicity of a substance in the form of NPs have been highlighted by many authors (e.g., [1-4]), and it is not among the objectives of this paper to discuss these grounds. It should be noted, however, that analysis of a great number of published data obtained in actual research supports the statement that "this common perception of greater nanoparticle toxicity is based on a limited number of studies" [5]. Moreover, some of the studies seem to contradict this "common perception" (e.g., $[6,7]$ ).

It has to be stressed, in this context, that although the problem of nanomaterials' health risk assessment and management is discussed widely and has been comprehensively reviewed by many authors (e.g., $[8,9]$ ), a general 
methodology of safe-exposure standards setting in this field is still lacking, and there are solitary examples of establishing or recommending reference exposure levels for specific engineered NPs in workroom air. Thus in most cases, the risk assessment and risk management scenarios still have to be implemented with qualification that exposure limits for individual nanomaterials are not available [10]. Given this serious uncertainty, the precautionary approach is that of choice in the worker's health protection in nanotechnology [11]. (The so-called precautionary principle aims at doing as little harm as is possible, unlike the widespread risk assessment approach which assumes that we know how much harm can be assimilated by a system (human being included) and so is allowable.) However, we believe that search for toxicological substantiation even if tentative, of presumably safe levels of exposure to specific nanomaterials should be intensified. In this respect, of the greatest importance is to understand, first of all, whether the host organism is able to recruit efficiently the usual physiological defences when exposed to NPs, because if not, even very low exposures it can deal with without noticeable harm are hardly possible, in principle.

In industrial conditions, and where ambient air is contaminated with the so-called "ultrafine aerosols," the adverse impact of NPs on the human organism is mainly associated with their deposition on free surfaces of the lower airways (or the "pulmonary region" in inhaled particles' biokinetics terms). The key mechanism controlling the self-clearance of the pulmonary region is the recruitment of cells which are capable of engulfing fine particles, thereby hindering their penetration into the pulmonary interstitium and promoting their elimination by mucociliary transport. The principal effector of this phagocytosis-mediated clearance mechanism is represented by pulmonary alveolar macrophages (AMs), with the auxiliary one being neutrophil leukocytes (NLs). The recruitment of NLs in response to the damaging effect of particles on AMs plays an important compensatory role. This recruitment is dependent on the amount of macrophage breakdown products, being thus the more intensive, the higher the damaging effect of particles on the macrophage (cytotoxicity) [12-15]. That is why the ratio of neutrophils to macrophages in the cell population of the bronchoalveolar lavage fluid is an indirect but quite reliable index of comparative cytotoxicity of different particles [12, 16-19].

It was to elucidate, however, to which degree these postulates, well established for particles in the micrometer range, apply to NPs as well. There is a widely proclaimed opinion that NPs are poorly recognized by protective mechanisms in general, inducing weak attraction of AMs and, therefore, are ineffectively eliminated from the lungs [2, 4]. This inefficiency would be rather strange from the evolutionary viewpoint, since all terrestrial vertebrates came to inhale nanoparticles (volcanic ash, seawater spray, smoke from forest fires, sulphates forming in the atmosphere as a result of the sulphur dioxide's oxidation, etc.) in the same epoch when they started to inhale microparticles, and all the physiological mechanisms of pulmonary clearance were present already in amphibians [20]. Although this speculation does not preclude the possibility of quantitative differences in the response of defence mechanisms under consideration to particles of different size, such differences are to be identified by accumulating concrete experimental data rather than theorising. In so doing, it is essential to compare only experimental results that have been obtained for the effects of nano- and microparticles of the same chemical nature whilst maintaining strict testing parallelism, which is not always observed. The same applies to comparative assessments of the systemic (resorptive) toxicity of NPs of different dimensions and that of microparticles.

In this paper, we shall overview and summarize main results of our studies of the nano- versus microparticles of $\mathrm{Fe}_{3} \mathrm{O}_{4}$ the particulars of which studies have been published in detail elsewhere $[19,21-23]$ and discuss, for the first time, some regulatory implications of those results.

\section{Materials and Methods}

For our study, we used three samples of chemically identical particles of magnetite $\left(\mathrm{Fe}_{3} \mathrm{O}_{4}\right)$ of identical magnetisation but of two different nanosizes (10 and $50 \mathrm{~nm}$ ) and one microsize ( $1 \mu \mathrm{m}$, i.e., $1000 \mathrm{~nm})$. The method of synthesizing these particles was described elsewhere [19, 21, 23], but it should be stressed here that their surface was not covered with any polymer or other chemical, and no surfactant was added to nanosuspensions.

In order to minimise the aggregation inherent in suspensions of many NPs, magnetic ones in particular, we (a) suspended them in deionised water and (b) elaborated a technique of intratracheal instillation of ultrasonically dispersed suspensions to rats. The procedure for drawing the suspension into a syringe and its injection into trachea under visual control fell within a time interval (28 s after the ultrasonication, on average) characterised by minimal aggregation of nanoparticles. The aggregation kinetics had been preliminarily studied by the method of dynamic light scattering on a Brookhaven ZetaPlus (USA) universal suspension analyser.

All compared particles were administered to outbred laboratory female rats:

(i) once intratracheally at a dose of $2 \mathrm{mg}$ in $1 \mathrm{~mL}$ of sterile deionised water because agglomeration in a suspension in normal saline had been found to occur too quickly;

(ii) or 3 times a week during 5 weeks intraperitoneally at a dose of $500 \mathrm{mg} / \mathrm{kg}$ in $4 \mathrm{~mL}$ of sterile deionised water.

Animals in respective control groups were administered water without particles by the same routes.

Along with optical microscopy of sedimented cells following the centrifuging of the bronchoalveolar lavage fluid (BALF), we examined the topography of the BALF cells surface under nanometric spatial resolution by the method of semicontact atomic force microscopy (sc-AFM) with the help of a scanning probe nanolaboratory NTEGRA Therma (Russia) using NSG01 probes with a tip height of 10-15 $\mu \mathrm{m}$ and a tip curvature radius of $10-15 \mathrm{~nm}$.

In a separate experiment, transmission electron microscopy (TEM) was used to study localisation of 
TABLE 1: Number of BALF cells 24 hours after intratracheal instillation of suspensions of magnetite particle $(2 \mathrm{mg} / \mathrm{mL})$ of various sizes to rats $(x \pm$ s.e. $)$.

\begin{tabular}{lcccc}
\hline Particle dia. & Total & $\begin{array}{c}\text { Number of cells, mln. } \\
\text { Alveolar macrophages (AMs) }\end{array}$ & Neutrophil leucocytes (NLs) & NL/AM ratio \\
\hline- & $2.53 \pm 0.36$ & $2.06 \pm 0.29$ & $0.30 \pm 0.05$ & $0.15 \pm 0.03$ \\
$10 \mathrm{~nm}$ & $18.57 \pm 3.20^{\mathrm{ac}}$ & $2.72 \pm 0.54$ & $14.99 \pm 2.57^{\mathrm{ac}}$ & $6.23 \pm 0.62^{\mathrm{ac}}$ \\
$50 \mathrm{~nm}$ & $26.37 \pm 5.12^{\mathrm{ac}}$ & $5.05 \pm 0.93^{\mathrm{abc}}$ & $20.65 \pm 4.37^{\mathrm{ac}}$ & $4.42 \pm 0.57^{\mathrm{abc}}$ \\
$1 \mu \mathrm{m}$ & $4.06 \pm 0.44^{\mathrm{ab}}$ & $1.81 \pm 0.24$ & $1.93 \pm 0.28^{\mathrm{ab}}$ & $1.32 \pm 0.27^{\mathrm{ab}}$ \\
\hline
\end{tabular}

a Designates values statistically significant difference from control group; ${ }^{\mathrm{b}}$ the same from " $10 \mathrm{~nm}$ " group; c the same from " $1 \mu \mathrm{m}$ " group $(P<0.05$ by Student's $t$-test).

magnetite NPs within the BALF cells and to visualize those damages to the cells at ultrastructural level that may be attributed to the cytotoxic effect of NPs. Based on the findings of the above experimental series, we selected just $10 \mathrm{~nm}$ NPs for the TEM study as particles that are the most actively phagocytised and, at the same time, the most cytotoxic ones.

Bronchoalveolar lavage was carried out 24 hours after the instillation of particles. A cannula connected to a Luer's syringe containing $10 \mathrm{~mL}$ of normal saline was inserted into the surgically prepared trachea of a rat under hexenal anaesthesia. The fluid entered the lungs slowly under the gravity of the piston, with the animal and syringe positioned vertically. Then the rat and the syringe were turned $180^{\circ}$, and the fluid flowed back into the syringe. The extracted BALF was poured into siliconized refrigerated tubes. An aliquot sample of the BALF was drawn into a WBC count pipette together with $3 \%$ acetic acid and methylene blue. Cell count was performed in a standard hemocytometer (the so-called Goryayev's Chamber). For cytological examination and semi-contact atomic force microscopy, the BALF was centrifuged for 4 minutes at $1000 \mathrm{rpm}$, then the fluid was decanted, and the sediment was used for preparing smears on 2 microscope slides. After air drying, the smears were fixed with methyl alcohol and stained with azure eosin. The smears were microscoped with immersion at a magnification of $\times 1000$. The differential count for determining the percentage of alveolar macrophages (AMs), neutrophil leucocytes (NLs), and other cells was conducted up to a total number of 100 counted cells. Allowing for the number of cells in the BALF, these percentages were recalculated in terms of absolute AM and NL counts.

For performing TEM, BALF was centrifuged for $30 \mathrm{~min}$ at $3000 \mathrm{rpm}$. The cell sediment was fixed in $2.5 \%$ solution of glutaraldehyde with subsequent additional fixing in $1 \%$ solution of osmium tetroxide for 2 hours, then it was washed in $0.2 \mathrm{M}$ phosphate buffer and passed through alcohols of increasing concentration and through acetone for dehydration. Then the sample was placed for 24 hours in a mixture of araldite and acetone at a ratio of $1: 1$, following which it was polymerized in araldite at $37^{\circ} \mathrm{C}$ for 1 day and then at $50-60^{\circ} \mathrm{C}$ for $2-3$ days. Ultrathin sections were obtained on a Leica EM UC6 ultramicrotome, contrasted with lead citrate, and examined on a Morgagni 268 electron microscope (USA).

The iron content of the lung, liver, and spleen tissues and of the blood was determined photometrically and additionally, for the liver and spleen tissues by the methods of atomic adsorption spectroscopy (AAS) using a SOLAAR M 6 atomic absorption spectrograph by Thermo Scientific (USA) and electron paramagnetic resonance (EPR) using EMX Plus spectrometer by Bruker (Germany).

All experiments were carried out on outbred white female rats with the initial body weight of 150 to $220 \mathrm{~g}$. All rats were housed in conventional conditions, breathed unfiltered air, were fed standard balanced food, and given clean water to drink. The experiments were planned and implemented in accordance with the International Guiding Principles for Biomedical Research Involving Animals developed by the Council for International Organizations of Medical Sciences (1985).

\section{Results and Discussion}

As can be seen from Table 1, the instillation of NPs of both sizes caused a much more intensive increase in the overall cell count of the BALF than the instillation of microparticles. However, this response to $10 \mathrm{~nm}$ particles was somewhat weaker than that to $50 \mathrm{~nm}$ ones. The latter difference was probably due to quicker clearance of the lungs from the finest particles, first of all, by virtue of their higher solubility. This hypothesis was confirmed in an additional experiment (Table 2): above-the-background (above the control level) iron content 24 hours after an injection of $10 \mathrm{~nm}$ magnetite particles was half the content in response to $50 \mathrm{~nm}$ and $1 \mu \mathrm{m}$ particles (in the absence of any difference between the latter two).

Judging by the increase in the NL/AM ratio, the cytotoxicity of $10 \mathrm{~nm}$ nanoparticles is a little higher than that of $50 \mathrm{~nm}$ NPs, with both fractions of the nanometer range being considerably more cytotoxic than the micrometer particles of the same substance (Table 1). (Above any doubt, given a certain size of NPs, both their cytotoxicity and pulmonary phagocytosis response strongly depend on their chemical nature, as it was found by us in comparative experiments with 3-4 nm NPs of silver and gold [23].) Thus, both nanoparticle size and perhaps some specific features of the nanostructure rendering a substance particularly biologically aggressive seem to also cause the elevated solubility of particles deposited in the lungs triggering accelerated pulmonary clearance and, hence, slower development of pathological changes. This dual effect of solubility has been well known long ago in relation to ultrafine condensation aerosols of silicon dioxide in comparison with quartz (e.g., [24]). 
TABLE 2: Iron content of rat lung tissue 24 hours after intratracheal instillation of $2 \mathrm{mg}$ of magnetite particles of various sizes or distilled water $(x \pm$ s.e. $)$.

\begin{tabular}{|c|c|c|c|}
\hline \multicolumn{4}{|c|}{ Groups of rats that were administered suspensions of particles with diameters } \\
\hline $10 \mathrm{~nm}$ & $50 \mathrm{~nm}$ & $1 \mu \mathrm{m}$ & Controls \\
\hline \multicolumn{4}{|c|}{ Iron content (mg/kg raw tissue) } \\
\hline $200 \pm 9^{a}$ & $257 \pm 8^{\mathrm{ab}}$ & $258 \pm 15^{\mathrm{ab}}$ & $141 \pm 5^{\mathrm{b}}$ \\
\hline \multicolumn{4}{|c|}{ Difference between group administered magnetite and controls } \\
\hline $59 \pm 10$ & $116 \pm 9^{b}$ & $117 \pm 16^{\mathrm{b}}$ & - \\
\hline
\end{tabular}

${ }^{\mathrm{a}}$ Designates values that are statistically significantly different from control value; ${ }^{\mathrm{b}}$ the same from the value for the group of rats administered $10 \mathrm{~nm}$ particles $(P<0.01$ by, $t$-test allowing for standard error of complex means, whereby data for each rat are considered as a sample consisting of 5 measurements $)$.

TABle 3: Percentage distribution of phagocytising cells with various degrees of particle burden 24 hours after intratracheal instillation of suspensions of magnetite particle $(2 \mathrm{mg} / \mathrm{mL})$ of various sizes to rats $(x \pm$ s.e. $)$.

\begin{tabular}{|c|c|c|c|}
\hline \multicolumn{2}{|c|}{ Alveolar macrophages (\%\%) } & \multicolumn{2}{|c|}{ Neutrophil leucocytes (\%\%) } \\
\hline with $\leq 20$ particles & with $>20$ particles & with $\leq 20$ particles & with $>20$ particles \\
\hline \multicolumn{4}{|c|}{24 hours after administration of $10 \mathrm{~nm}$ particles. } \\
\hline $9.38 \pm 0.25 \%^{\mathrm{b}}$ & $90.62 \pm 0.35 \%^{\mathrm{b}}$ & $42.66 \pm 0.28 \%^{b}$ & $57.34 \pm 0.38 \%^{\mathrm{b}}$ \\
\hline \multicolumn{4}{|c|}{24 hours after administration of $50 \mathrm{~nm}$ particles. } \\
\hline $19.09 \pm 0.21 \% \mathrm{ab}$ & $80.91 \pm 0.21 \%{ }^{\mathrm{ab}}$ & $72.55 \pm 0.18 \%{ }^{\mathrm{ab}}$ & $27.45 \pm 0.19 \%$ ab \\
\hline \multicolumn{4}{|c|}{24 hours after administration of $1000 \mathrm{~nm}$ particles. } \\
\hline $64.00 \pm 0.16 \%^{\mathrm{a}}$ & $36.00 \pm 0.16 \%^{\mathrm{a}}$ & $97.75 \pm 0.08 \%^{\mathrm{a}}$ & $2.25 \pm 0.08 \%{ }^{\mathrm{a}}$ \\
\hline
\end{tabular}

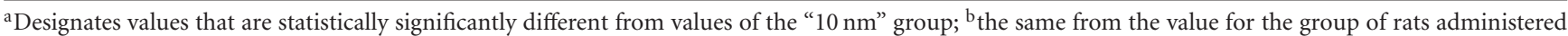
$1000 \mathrm{~nm}$ particles $(P<0.001$ by $t$-test allowing for standard error of complex means, whereby data for each rat are considered as a sample consisting of $n$ cells).

In 24 hours in vitro assays on the $\mathrm{A} 3$ human $\mathrm{T}$ lymphocytes with iron oxide nanoparticles of the same dimensions (10 $\mathrm{nm}$ and $50 \mathrm{~nm}$ ), it was also found that NPs of the smaller size were more cytotoxic than those of the larger size, although in the same terms of mass concentration there was no size dependence of NPs toxicity found in 1-hour assays [25]. The analysis of available literature shows that, in general, results of comparative particulates cytotoxicity assessment strongly depend on cell type and assays chosen by investigators and on conditions of exposure. Thus, researchers [7] who compared on human cell line A549 cytotoxicity of nano- and micrometer particles of $\mathrm{Fe}_{2} \mathrm{O}_{3}, \mathrm{Fe}_{3} \mathrm{O}_{4}, \mathrm{TiO}_{2}$, and $\mathrm{CuO}$ using a number of indices concluded that "nanoparticles are not always more toxic than micrometer particles" and, specifically, the iron oxides showed low toxicity with no clear difference between the different particle sizes. Our in vivo results clearly contradict this conclusion.

Counting the particles observable inside the phagocytising cells by means of immersion optical microscopy with a magnification of $\times 1000$ (Table 3 ) revealed that AMs and NLs "loaded" with fewer particles constituted a 1.7-2.0 times smaller percentage of the total number of corresponding cells in the BALF from the lungs injected with $10 \mathrm{~nm}$ particles in comparison with those injected with $50 \mathrm{~nm}$ ones. Thus, phagocytosis was less active in the latter; however, NPs of both sizes were engulfed by both macrophages and neutrophils much more avidly than micrometer particles. The particularly avid phagocytosis of $10 \mathrm{~nm}$ particles is another probable cause of their above-mentioned less substantial retention in the lungs. It is known that macrophage breakdown products stimulate both the attraction of AMs and, especially, of NLs and the phagocytic activity of macrophages in relation to $1 \mu \mathrm{m}$ polystyrene test particles [17]. This suggests an explanation for the direct relationship between the cytotoxicity of magnetite particles of different size, and the avidity with which viable phagocytes engulf them.

Micropits discovered on the surfaces of BALF cells with the aid of the sc-AFM (Figure 1) may be interpreted as marks left by plasma membrane invagination in the course of particle phagocytosis. The visual assessment of the dependence of the number and diameters of these micro-pits on magnetite particle size was confirmed by measurements of the above diameters and by statistical analysis of the results (Figure 2). Here, again we can see that phagocytosis was maximal in response to $10 \mathrm{~nm}$ particles and minimal in response to $1 \mu \mathrm{m}$ particles; the number of the largest micropits per cell unit area was, naturally, greatest for 1 micrometer particles and lowest for $10 \mathrm{~nm}$ ones (Figure 3).

Figure 4 shows a typical electron microscopy picture of the AM's periphery for rats exposed to $10 \mathrm{~nm}$ magnetite. It can be seen that extracellular singlet NPs or preformed finest aggregates consisting of 2 or 3 primary NPs are located at a short distance from or in direct contact with the plasma membrane. If located within the cell, they are found in the vacuoles separated from the cytoplasm matrix by a twocontour membrane. These finest phagosomes are known to form as a result of separation of an invaginated area of the cell's plasma membrane. It can be seen that one such phagosome is in close contact with the internal contour of the plasma membrane, from which, apparently, it has just got nipped off. Visible close to it are NPs at the beginning 


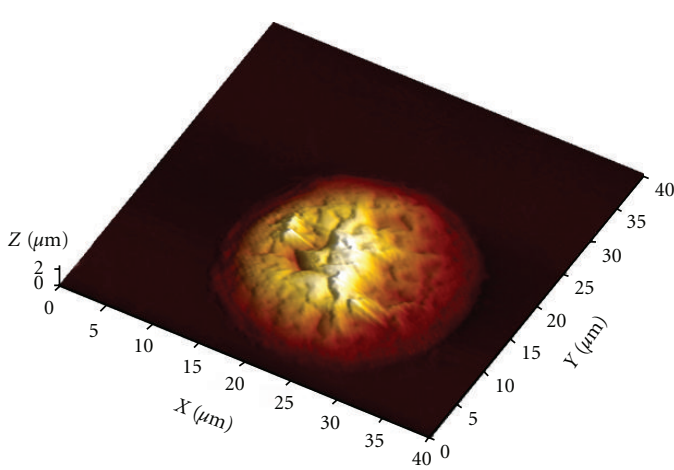

(a)

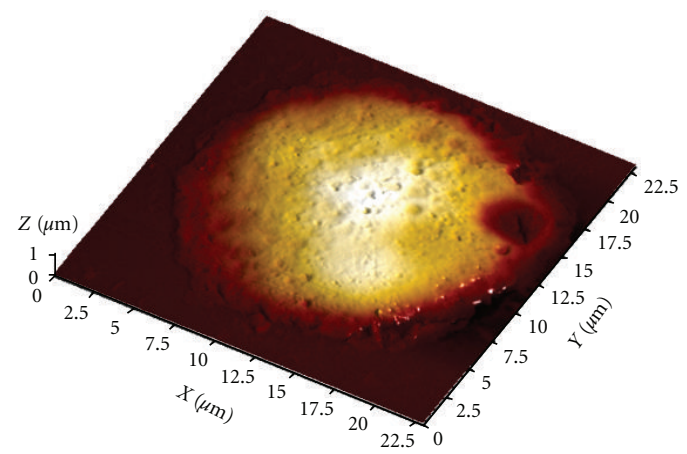

(c)

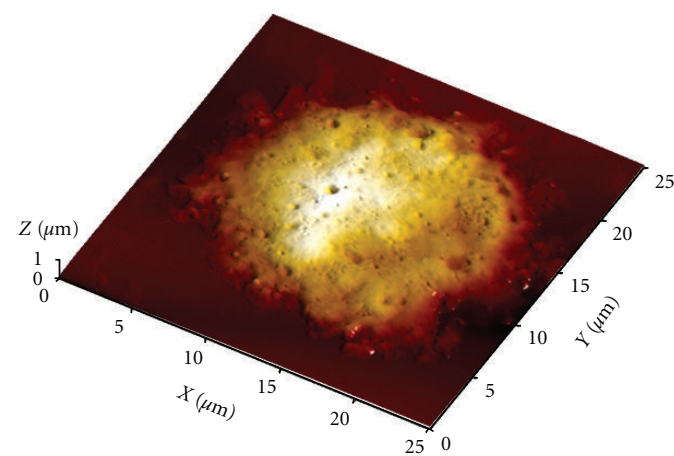

(e)

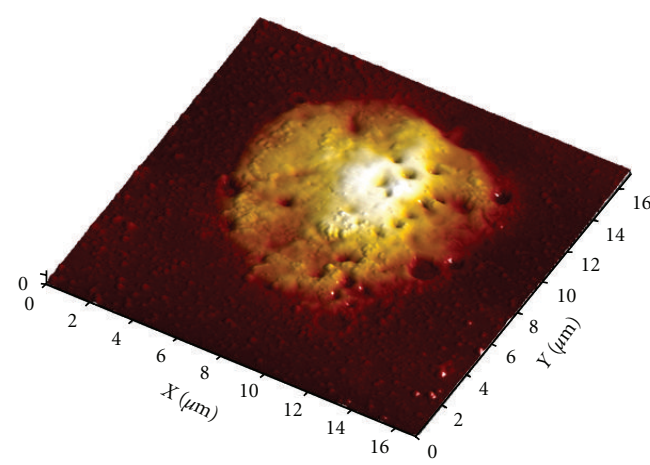

(g)

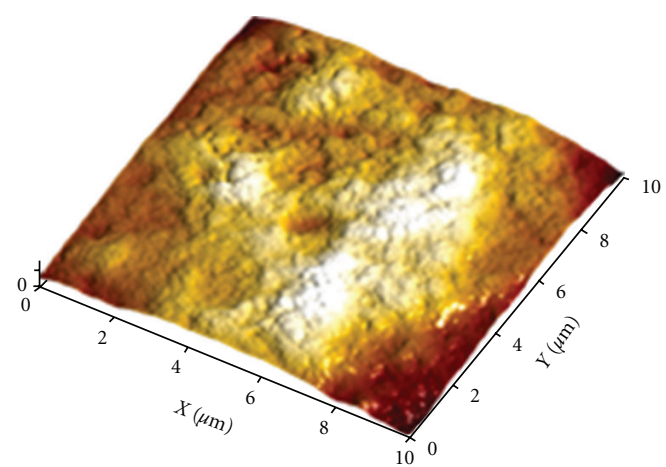

(b)

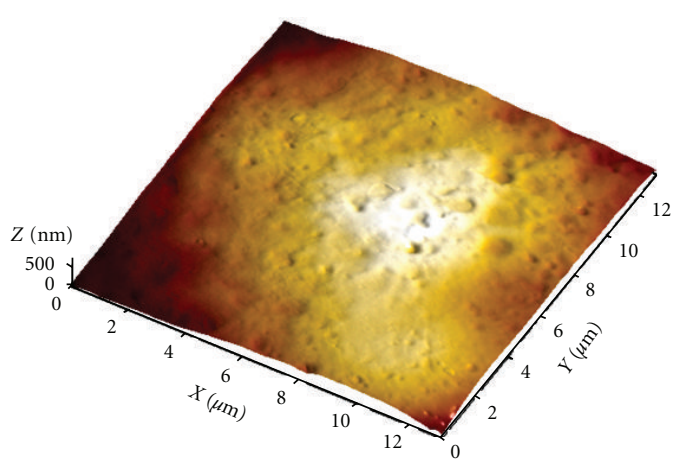

(d)

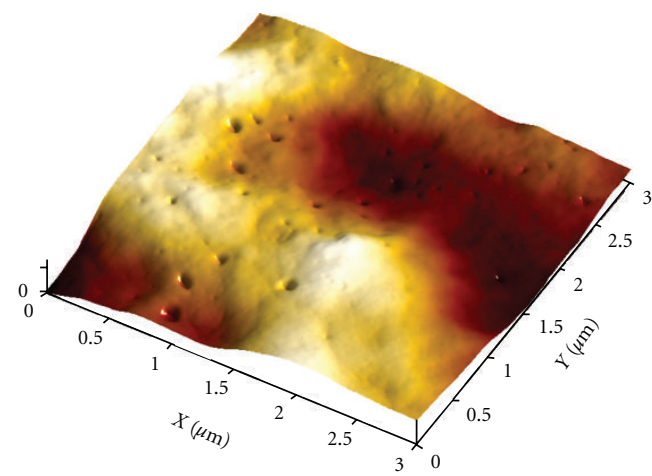

(f)

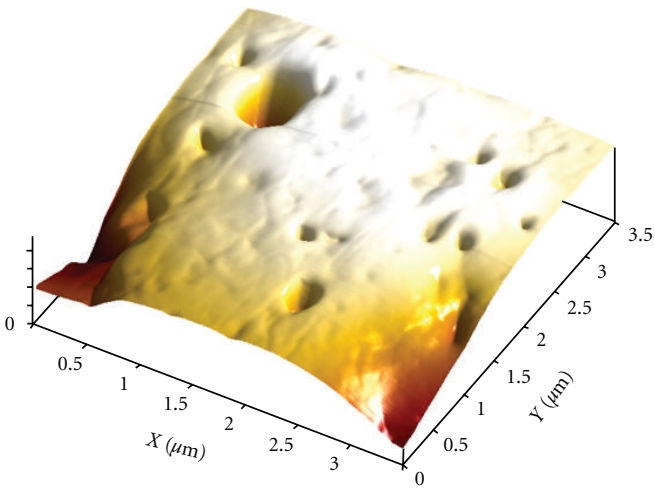

(h)

FIGURE 1: Typical cell surface topography measured by semicontact AFM, for various groups of samples: (a), (b) controls; (c), (d) after instillation of $10 \mathrm{~nm}$ magnetite; (e), (f) $50 \mathrm{~nm}$ magnetite; (g), (h) $1 \mu \mathrm{m}$ magnetite. 


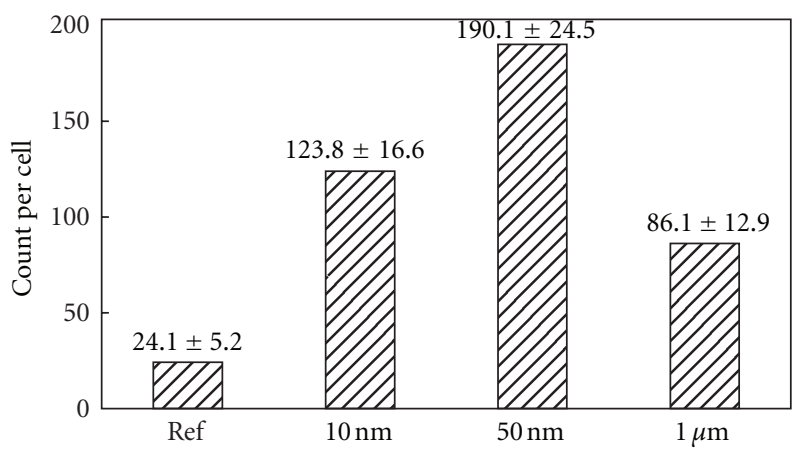

(a)

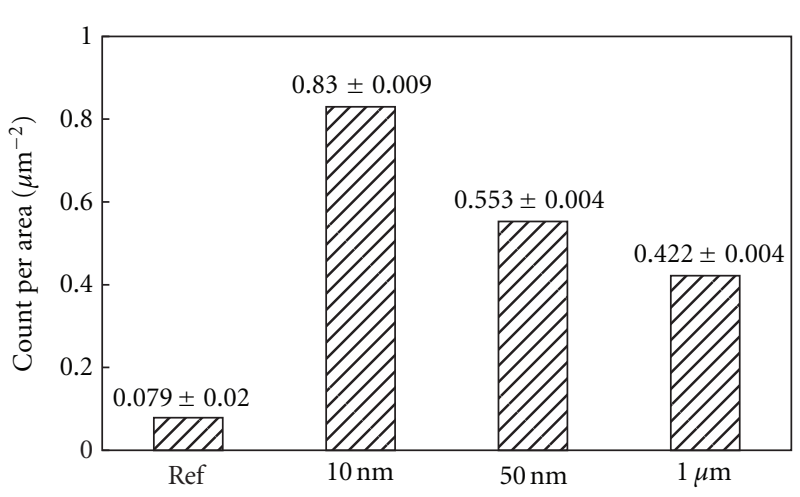

(b)

Figure 2: Average number (a) and average surface concentration (b) of micropits of all transverse dimensions detected on the surfaces of cells of each group $(x \pm$ s.d.) (ref: values from the control group).

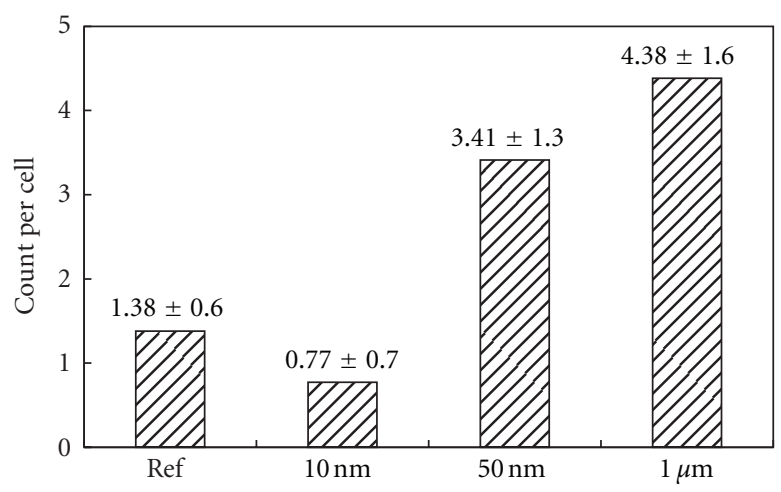

(a)

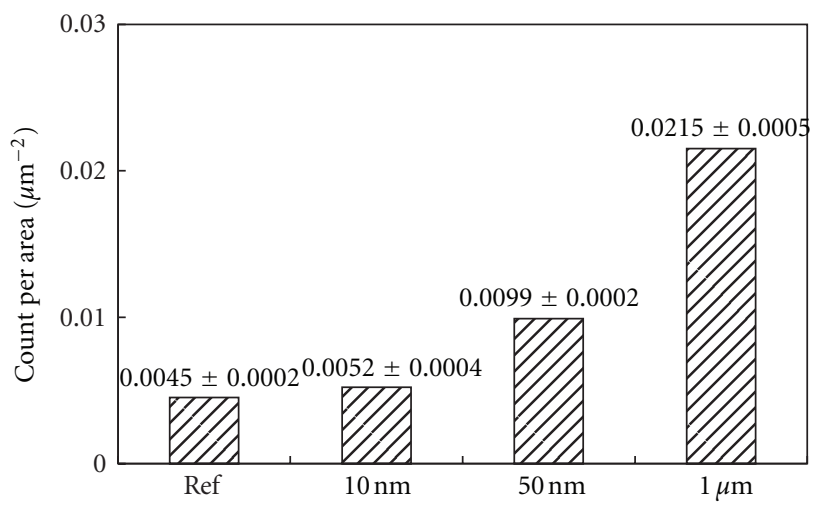

(b)

Figure 3: Average number (a) and average concentration (b) of micropits with a transverse dimension of $>1 \mu \mathrm{m}$ detected on the surface of cells of each group $(x \pm$ s.d.) (ref: values from the control group).

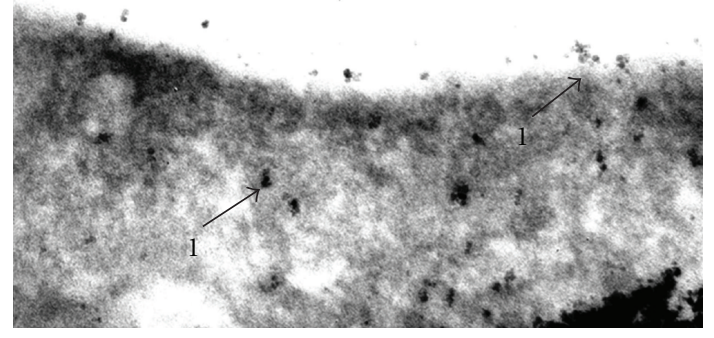

Figure 4: Engulfment of $10 \mathrm{~nm}$ magnetite particles by an AM (phagosomes, arrows 1). TEM, magnification $* 140000$.

of invagination. It should be qualified, however, that in many cases, the boundaries of phagosomes are not clear, and so many NPs visible within a cell could be distributed in cytoplasm in a free state. Whether it is a result of their direct physical penetration (diffusion) through the cell membrane or that of their secondary liberation after the phagosome's breakdown (see below) is a matter of conjecture and discussion.
None of the ultrasections revealed any pattern that would point to phagocytosis of preformed large conglomerates of micrometer size similar to those seen intracellulary under optical microscopy with $\times 1000$ magnification. At the same time, electron microscopy also reveals a considerable number of such conglomerates inside AM, being separated, in most cases, by a two-contour membrane (Figure 5), that is, located inside a large endosome (phagosome) presumably resulting from a fusion of finer phagosomes. In cases where no such separating membrane is visible around NPs conglomerates located in the cytoplasm, we most likely observe a secondary phenomenon associated with the breakdown of the endosomal membrane as a result of the damage caused to it by NPs. This damaging effect is most conspicuous where such free conglomerate of NPs is seen in contact with the membranes of other organelles (particularly often with those of mitochondria) or with the nucleus membrane as is shown in Figures 6 and 7. Within mitochondria, NPs are found on the membrane and cristae, sometimes filling the matrix up. In these cases, we can observe disturbance of the two-contour appearance of the membranes, breakdown of cristae, and clarification of the mitochondrial matrix. Other researchers [4] have shown that unlike the "coarse fraction" of atmospheric particles, which are detected only 


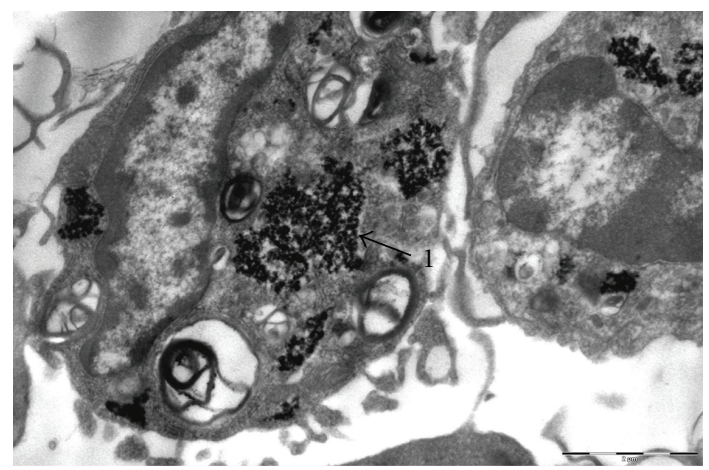

Figure 5: $10 \mathrm{~nm}$ magnetite particles in an $\mathrm{AM}$ gathered within endosomes (arrow 1). TEM, magnification $* 8900$.

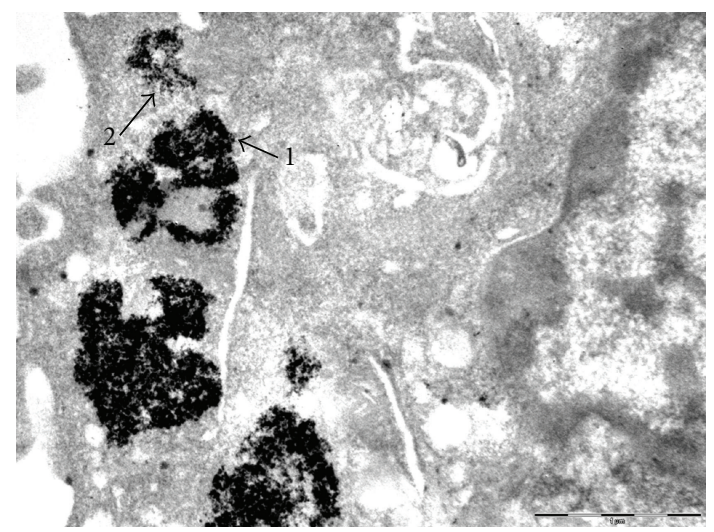

Figure 6: Contact of clustered $10 \mathrm{~nm}$ magnetite particles with membranes (arrow 1) and cristae (arrow 2) of AM's mitochondria. TEM, magnification $* 22000$.

within phagosomes in response to in vitro exposure of macrophagelike cells, "ultrafine fraction" particles (up to $150 \mathrm{~nm}$ ) are observed to be in contact with mitochondria, causing damage to them and related oxidative stress.

Notable in our experiment is the almost total absence of primary lysosomes, which are present in large numbers in the AMs of control animals. This is possibly due to the damaging effect of NPs on the Golgi apparatus responsible for the formation of lysosomes. We cannot rule out, however, that the disappearance of lysosomes can be a result of the fusion between these organelles and numerous phagosomes (i.e., the formation of phagolysosomes, or the so-called secondary lysosomes). Following the disruption of phagolysosomal membranes, the liberation of liposomal hydrolases into the cytoplasm is likely to be an important additional mechanism of cell damage and destruction. The role of this macrophage "self-digestion" at exposure to cytotoxic microparticles was postulated a long time ago [26] and has found its way into the circle of classical ideas concerning the mechanisms of cytotoxicity of such particles, the quartz ones in particular, for macrophages [17]. Indeed, under electron microscopy, we found quite a few completely destroyed AMs with NPs and their conglomerates that had escaped into the intercellular space.

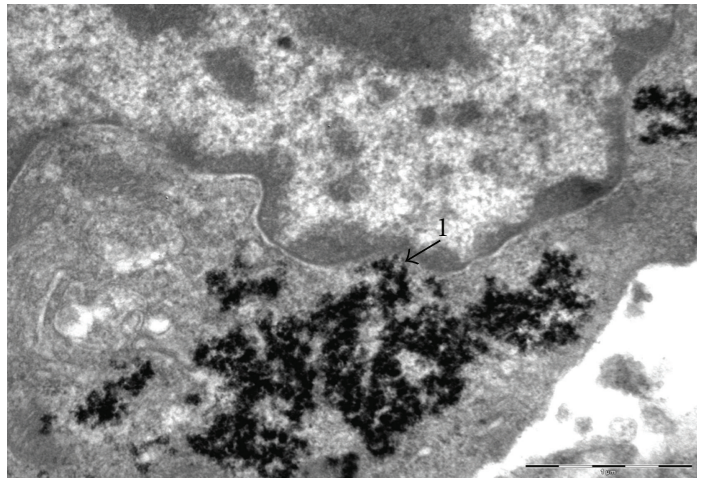

FIGURE 7: Contact (arrow 1) of clustered $10 \mathrm{~nm}$ magnetite particles with the damaged nuclear membrane of an AM. TEM, magnification $* 22000$.

Thus, the results of both sc-AFM and TEM confirm that the AM is quite capable of recognizing and phagocytising even the finest particles of the nanometric range. Here we do not deal with the mechanical penetration or, in any case, not just the mechanical penetration of such NPs through the plasma membrane but mainly with an active physiological process following the general pattern of phagocytosis of any solid particles. Moreover, there are sufficient grounds to believe that the formation of intracellular conglomerates of NPs is essentially linked not simply to their special predilection to physical aggregation characteristic of all NPs (especially magnetic ones) in liquid medium, but also to the same physiological process at the stage during which fine phagosomes fuse into larger ones inside which this predilection manifests itself. Finally, the findings provide evidence in favour of the hypothesis that, as well as in response to the impact of mineral microparticles, the primary cause of NPs cytotoxicity for AM is their membranolytic activity.

Judging by the majority of the functional indices given in Table 4, both $10 \mathrm{~nm}$ and $50 \mathrm{~nm}$ magnetite particles cause a greater number of statistically significant adverse shifts in response to subchronic intraperitoneal exposure than $1 \mu \mathrm{m}$ particles do, these indices tending to be the most marked for $10 \mathrm{~nm}$ NPs. The majority of shifts are of a nonspecific character, being integral indices of intoxication, but the response of the red blood is likely to be related to the specific role of iron in haemopoiesis. Moreover, the increase in haemoglobin content of the blood was statistically significant in response to the administration of finest magnetite NPs along with a significant (and greatest) increase in the number of erythrocytes and especially in the proportion of reticulocytes in them. The latter shift points to a stimulation of erythropoiesis, which, in the case of $10 \mathrm{~nm}$ particles, reaches a degree characterized by a significant rise in the overall RBC count and the haemoglobin content. It may be assumed that increased demand for iron for heme synthesis leads to its significantly less elevated content in the blood serum in comparison with controls in response to injection of $10 \mathrm{~nm}$ magnetite particles versus $50 \mathrm{~nm}$ ones, in spite of the fact that the former possess higher solubility. At the same time, the fact that $1 \mu \mathrm{m}$ magnetite yielded the least and 
TABLE 4: Some indices to the status of the organism of rats under subchronic intraperitoneal exposure to magnetite particles of different size during 5 weeks up to total dose of $7500 \mathrm{mg}$ per kg body mass $(x \pm$ s.e. $)$.

\begin{tabular}{|c|c|c|c|c|}
\hline \multirow{3}{*}{ Indices } & \multicolumn{4}{|c|}{ Groups of rats } \\
\hline & \multirow{2}{*}{ Control group } & \multicolumn{3}{|c|}{ Rats exposed to magnetite particles of nominal size } \\
\hline & & $10 \mathrm{~nm}$ & $50 \mathrm{~nm}$ & $1 \mu \mathrm{m}$ \\
\hline Initial body mass, $\mathrm{g}$ & $184.23 \pm 1.11$ & $184.62 \pm 1.55$ & $186.15 \pm 1.15$ & $185.38 \pm 1.32$ \\
\hline Body mass after the exposure period, $g$ & $215.42 \pm 3.96$ & $213.46 \pm 2.85$ & $218.46 \pm 2.91$ & $219.6 \pm 4.5$ \\
\hline Number of head dips into holes during $3 \mathrm{~min}$ & $7.67 \pm 1.07$ & $4.08 \pm 0.86^{\mathrm{a}}$ & $4.45 \pm 0.87^{\mathrm{a}}$ & $4.0 \pm 0.6^{\mathrm{a}}$ \\
\hline Hemoglobin, g/L & $130.13 \pm 2.94$ & $140.70 \pm 4.13^{c}$ & $134.1 \pm 3.7$ & $126.74 \pm 3.29$ \\
\hline Reticulocytes, \%o & $11.3 \pm 0.7$ & $53.62 \pm 1.91^{\mathrm{abc}}$ & $36.73 \pm 1.21^{\mathrm{ac}}$ & $14.72 \pm 1.24^{\mathrm{a}}$ \\
\hline SDH activity, number of granules per 50 lymphocytes & $764.7 \pm 15.2$ & $692.73 \pm 8.7^{\mathrm{ac}}$ & $703.5 \pm 8.6^{\mathrm{ac}}$ & $762.30 \pm 10.95$ \\
\hline Lymphocytes, \% & $54.42 \pm 2.02$ & $44.08 \pm 1.68^{\mathrm{ac}}$ & $43.5 \pm 3.1^{\mathrm{a}}$ & $51.0 \pm 2.4$ \\
\hline Segmented neutrophils, \% & $28.92 \pm 2.07$ & $41.23 \pm 1.81^{\mathrm{ac}}$ & $40.85 \pm 2.71^{\mathrm{ac}}$ & $30.67 \pm 3.15$ \\
\hline Band neutrophils, \% & $1.08 \pm 0.19$ & $1.38 \pm 0.18$ & $1.92 \pm 0.26^{\mathrm{a}}$ & $1.42 \pm 0.19$ \\
\hline Total protein content of blood serum, g/L & $78.23 \pm 1.56$ & $60.64 \pm 2.03^{\mathrm{ac}}$ & $65.69 \pm 2.13^{\mathrm{ac}}$ & $76.73 \pm 1.79$ \\
\hline Albumin in blood serum, $\mathrm{g} / \mathrm{L}$ & $44.09 \pm 1.39$ & $41.22 \pm 2.18$ & $36.91 \pm 1.78^{\mathrm{a}}$ & $38.94 \pm 1.33^{\mathrm{a}}$ \\
\hline Globulins in blood serum, $\mathrm{g} / \mathrm{L}$ & $34.14 \pm 1.30$ & $19.42 \pm 1.47^{\mathrm{abc}}$ & $28.79 \pm 2.21^{\mathrm{c}}$ & $37.8 \pm 1.8$ \\
\hline Albumin/globulin ratio & $0.79 \pm 0.05$ & $0.50 \pm 0.06^{\mathrm{abc}}$ & $0.82 \pm 0.09$ & $0.99 \pm 0.07^{\mathrm{a}}$ \\
\hline Alkaline phosphatase in blood serum, $\mathrm{nMol} /(\mathrm{s} * 1)$ & $928.18 \pm 127.05$ & $1244.9 \pm 213.4^{\mathrm{c}}$ & $1144.67 \pm 143.90^{c}$ & $700.51 \pm 76.92$ \\
\hline$\gamma$-glutamin transferase activity in blood serum, $\mathrm{nMol} /(\mathrm{s} * \mathrm{l})$ & $1889.12 \pm 126.90$ & $2408.76 \pm 118.46^{\mathrm{ac}}$ & $2294.48 \pm 131.39^{\mathrm{a}}$ & $1982.77 \pm 71.1$ \\
\hline AST activity in blood serum, $\mathrm{mM} /(\mathrm{h} * \mathrm{l})$ & $1.25 \pm 0.04$ & $1.31 \pm 0.04^{\mathrm{c}}$ & $1.29 \pm 0.04^{\mathrm{c}}$ & $1.13 \pm 0.04^{\mathrm{a}}$ \\
\hline De Ritis coefficient & $1.29 \pm 0.07$ & $1.70 \pm 0.14^{\mathrm{ab}}$ & $1.33 \pm 0.07$ & $1.4 \pm 0.1$ \\
\hline Iron in blood serum, mg/L & $4.23 \pm 5.12$ & $9.22 \pm 1.02^{\mathrm{ab}}$ & $14.4 \pm 0.93^{\mathrm{ac}}$ & $5.05 \pm 0.42$ \\
\hline MDA in blood serum, nMol/L & $4.39 \pm 0.11$ & $6.01 \pm 0.36^{\mathrm{ac}}$ & $6.3 \pm 0.3^{\mathrm{ac}}$ & $4.42 \pm 0.11$ \\
\hline Ceruloplasmin in blood serum, $\mathrm{mg} / \mathrm{L}$ & $23.72 \pm 2.05$ & $31.45 \pm 1.95^{\mathrm{ac}}$ & $27.77 \pm 1.80$ & $24.78 \pm 2.16$ \\
\hline Daily urine volume, $\mathrm{mL}$ & $30.3 \pm 3.6$ & $40.56 \pm 4.46$ & $44.80 \pm 3.55^{\mathrm{ac}}$ & $34.90 \pm 2.54$ \\
\hline Coproporphyrin in urine $\mathrm{nM} / \mathrm{L}$ & $71.15 \pm 9.80$ & $127.49 \pm 23.17^{\mathrm{a}}$ & $121.18 \pm 18.99^{\mathrm{a}}$ & $142.83 \pm 25.02^{\mathrm{a}}$ \\
\hline Coproporphyrin in urine $\mathrm{nM} / 24 \mathrm{~h}$ & $2.05 \pm 0.28$ & $4.86 \pm 0.96^{\mathrm{a}}$ & $4.99 \pm 0.86^{\mathrm{a}}$ & $4.98 \pm 1.15^{\mathrm{a}}$ \\
\hline$\delta$-ALA in urine $\mu \mathrm{M} / 24 \mathrm{~h}$ & $0.34 \pm 0.04$ & $0.42 \pm 0.07$ & $0.58 \pm 0.06^{\mathrm{ac}}$ & $0.39 \pm 0.04$ \\
\hline Creatinine in urine, $\mathrm{mMol} / \mathrm{L}$ & $0.12 \pm 0.02$ & $0.16 \pm 0.02$ & $0.24 \pm 0.04^{\mathrm{ac}}$ & $0.12 \pm 0.01$ \\
\hline Creatinine in urine, $\mu \mathrm{Mol} / 24 \mathrm{~h}$ & $4.07 \pm 0.91$ & $6.78 \pm 1.42$ & $11.25 \pm 2.16^{\mathrm{ac}}$ & $4.24 \pm 0.57$ \\
\hline Spleen mass, $g$ & $0.81 \pm 0.04$ & $1.01 \pm 0.11$ & $1.05 \pm 0.09^{\mathrm{a}}$ & $0.89 \pm 0.08$ \\
\hline Liver mass, $\mathrm{g}$ & $7.44 \pm 0.37$ & $9.13 \pm 0.27^{\mathrm{a}}$ & $9.34 \pm 0.49^{\mathrm{a}}$ & $7.94 \pm 0.52$ \\
\hline
\end{tabular}

${ }^{a}$ Designates values that are statistically significantly different from control values; ${ }^{b}$ the same from the value for the group of rats administered $50 \mathrm{~nm}$ particles; ${ }^{c}$ the same from the " $1 \mu \mathrm{m}$ " group ( $P \leq 0.05$ by Student $t$-test).

statistically insignificant increase in this index corresponds well with the lowest solubility of this fraction.

The interpretation of comparative biokinetics of intraperitoneally injected magnetite particles of different size is complicated by the fact that it is not only iron absorbed in its ion-molecular form but also not dissolved NPs that can penetrate into the blood and, thus, can be transferred into the parenchymatous organs from the primary depot, this ability for direct penetration (presumably characteristic of all NPs) being the higher, the finer they are. When retained in organs rich in reticuloendothelial cells, NPs keep dissolving already in these organs, and this process, especially characteristics of the finest NPs by virtue of the greatest surface area, may limit the ultimate accumulation of iron in the tissue. The measurement of the iron contents of liver and spleen tissues gave results quite consistent with these hypotheses. As is shown by Figure 8, the concentration of total iron as determined by the AAS method in the liver and spleen is much higher following the administration of magnetite NPs as compared with micrometer particles, for which it is only slightly and statistically insignificantly higher than in the organs of control rats. However, in both organs (especially in the spleen), it is somewhat lower for rats injected with $10 \mathrm{~nm}$ NPs in comparison with $50 \mathrm{~nm}$ NPs. Iron in the initial chemical form of magnetite (which may appear in a tissue only if nondissolved particles have been transferred into it) determined by the EPR method (Figure 9) is practically absent in both control rats, and those exposed to $1 \mu \mathrm{m}$ magnetite (most probably, due to the insignificant ability of micrometric particles to penetrate into blood from the primary peritoneal depot), but following an injection of NPs of both sizes, its content is very great in the liver and especially in the spleen, again being somewhat lower in both organs in the case of $10 \mathrm{~nm}$ NPs.

Other experimental results [27] also give a retrospective support to the above speculations of ours concerning complicated character of mechanisms oppositely controlling bioaccumulation of NPs in organs rich in cells of 


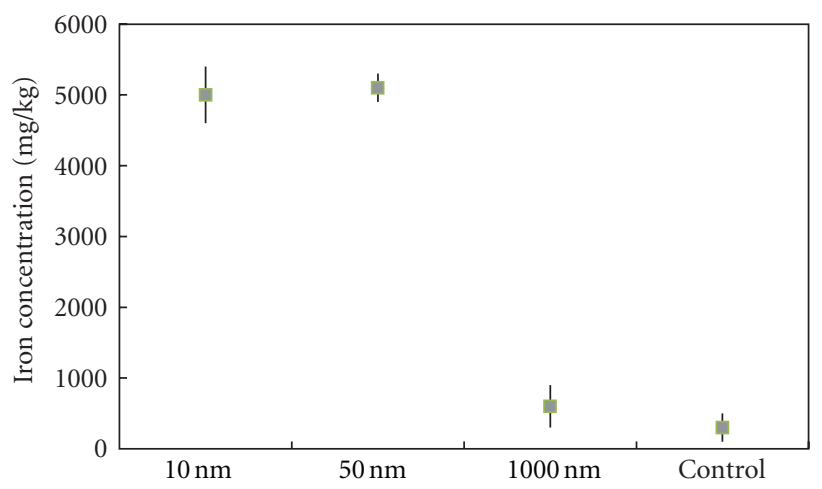

(a)

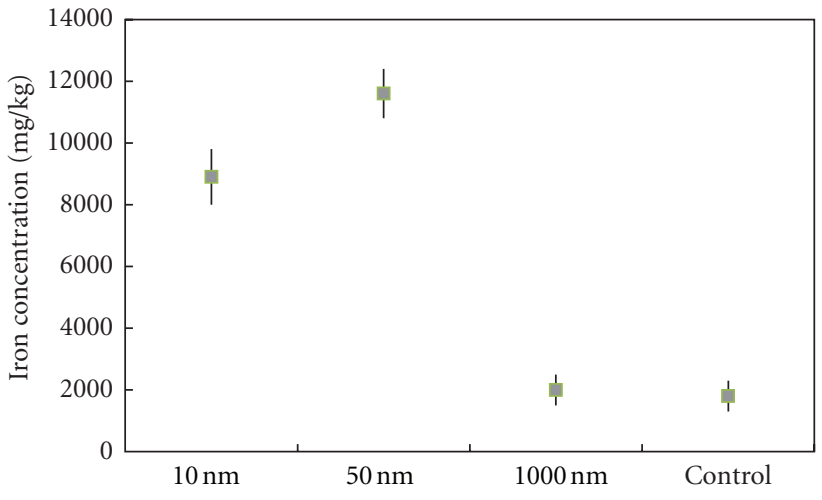

(b)

FIgURE 8: Mean value ( \pm s.d.) of total iron concentration in the rat tissues of (a) liver and (b) spleen by groups of rats exposed to magnetite particles of different size. AAS method.

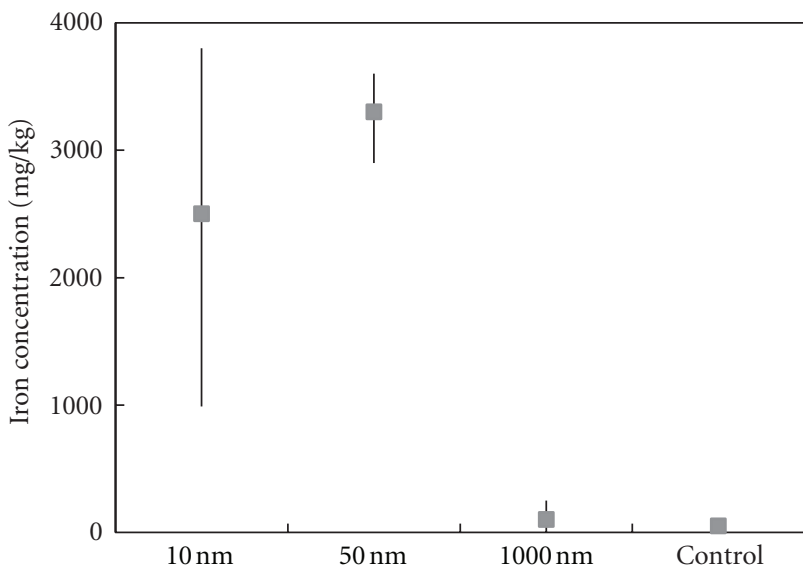

(a)

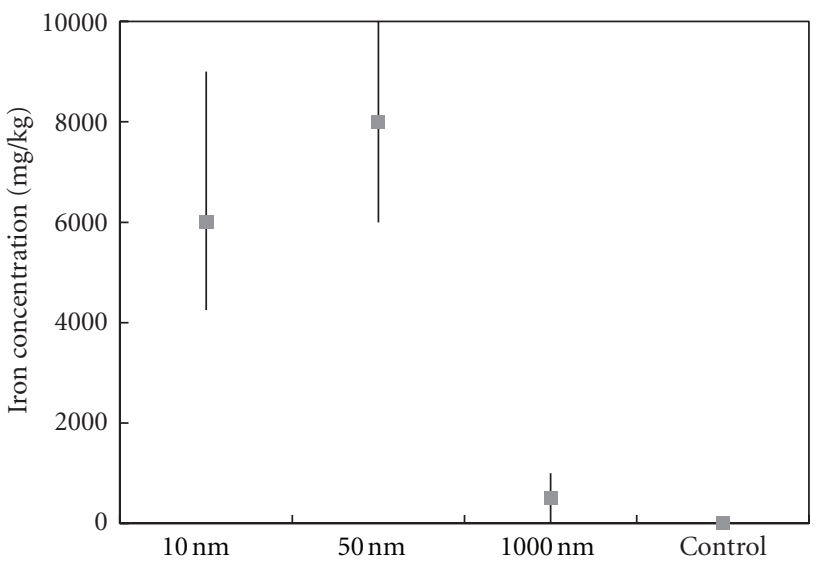

(b)

FIGURE 9: Mean value ( \pm s.d.) of iron concentration in the form of magnetite in the rat tissues of (a) liver and (b) spleen by groups of rats exposed to magnetite particles of different size. EPR method.

mononuclear phagocytic system. For instance, these authors found that at early time points up to 3 hours after a single intraperitoneal injection to mice of dextran-coated magnetic iron oxide NPs with mean diameter $57 \mathrm{~nm}$ ("small") or $30 \mathrm{~nm}$ ("ultrasmall") the Prussian-blue-stained areas in the liver were much larger in the case of ultrasmall NPs. However, at 12 and at $24 \mathrm{hrs}$, this difference diminished due to a sharp decrease in the ultra small NPs' retention along with some increase in the small NPs' retention, and at $48 \mathrm{hrs}$, the latter prevailed. Thus, in the final count, the longterm liver retention of iron injected i.p. with intrinsically less penetrating larger NPs may be greater as compared with smaller NPs- just what we found after repeated injections to rats of 50 versus $10 \mathrm{~nm}$ magnetite. It should be understood, of course, that the most important prerequisite for this pattern of retention is a sufficient ability of particles to penetrate into blood (as to be then retained in organs), and so still bigger particles (in our experiment-1000 nm), whose penetration may be considered negligible, did not cumulate in liver virtually at all.

That accumulation of iron in tissues may be redundant and may lead to its well-known pathological consequences (hypersiderosis) is evidenced, in our experiment, by histopathological changes in the liver and the spleen. In the livers of the rats exposed to NPs, the structure of the lobules is disturbed; there is discomplexation of the liver trabeculae due to the deposition of a considerable amount of iron-containing pigment in the form of conglomerates in the periportal zones, intralobularly, occasionally centrilobularly, and in the form of individual particles in the sinusoids. Iron-containing pigment is also identifiable in the Kupffer cell's cytoplasm. Hepatocytes are in a state of profound vacuolar dystrophy, with occasional cytolysis. The extent and breadth of pathological changes are somewhat higher for $50 \mathrm{~nm}$ compared with $10 \mathrm{~nm}$ magnetite. Thus, the higher hepatotoxicity of the former corresponds to higher accumulation of nanoparticles in the organ. As for changes in the livers of rats exposed to 1 micron magnetite, they are minimal, which may be attributed to both an insignificant amount of this material going into the liver and its lower toxicity for tissues. In the spleen, considerably more marked changes are observed in response to NPs of both sizes (extensive deposits of iron-containing lumps in the red pulp and, occasionally, in compressed follicles of the white pulp, in which light reactive centres are observable) in comparison with micrometer ones, for which the histological picture 
of this organ is not very much different from that of the controls. (The color microphotographs of histological preparations illustrating these pathological changes and some morphometrical data pertaining to them were published by Katsnelson et al. [21].)

On the whole, our study permits us to maintain that the widespread concept of quasi-defenselessness of organism against NPs should be critically reevaluated. On the other hand, it provides evidence supporting the prevailing presumption that substances in particulate form, even ones that are relatively biologically inert in the micrometer range, may be markedly toxic in the nano-state. However, within the conventional nanometer range, the dependence of toxicity on particle size is intricate and nonunique.

Therefore we maintain that

(a) tentative reference level (TRL) for assessing exposures to iron oxide NPs contaminating workroom air should be significantly lower as compared with actual exposure limits established (or recommended) for chemically identical microparticles;

(b) there are no reliable foundations for establishing such TRLs as different for NPs of different size.

As to an already existing example of such approach, we may refer to the REL $0.3 \mathrm{mg} / \mathrm{m}^{3}$ recommended by the $\mathrm{NIOSH}$ for the ultrafine (including engineered nanoscale) $\mathrm{TiO}_{2}$ that is 8 times lower than REL $2.4 \mathrm{mg} / \mathrm{m}^{3}$ for the fine $\mathrm{TiO}_{2}$ [28]. The NIOSH maintains that "similarly for other particulate materials, if the toxicity varies by particle size (at the same mass dose), distinct exposure limits for distinct particle size fractions might be a reasonable approach for protecting exposed workers." Meanwhile, the $\mathrm{TiO}_{2}$ nanopowders are being manufactured and marketed for a variety of uses in a rather wide range of primary particles diameters (e.g., ca. $10 \mathrm{~nm}, 10-30, \leq 50 \mathrm{~nm}$ ). Thus, we may say that the NIOSH REL for any engineered nano- $-\mathrm{TiO}_{2}$ is in good accordance with, though established independently of, the above postulates (a) and (b).

A similar but even more conservative approach to establishing exposure standards for engineered nanomaterials is proposed by the Australian Government agency "Safe Work Australia" [29] for nanocrystals, quantum dots, ceramic oxides, and metals, and the suggested Benchmark Exposure Level (BEL) should be $0.066 *$ WEL (where WEL stands for Workplace Exposure Limit for bulk material).

Although in different countries workroom exposure standards are established for only one iron oxide, namely $\mathrm{Fe}_{2} \mathrm{O}_{3}$, it may be assumed that there is no significant difference in toxicity between different iron oxides. For instance, it is by no chance that the Joint Expert Committee on Food Additives (JEFCA) gives one and the same acceptable daily intake value for $\mathrm{Fe}_{3} \mathrm{O}_{4}$ (the so-called black iron (II, III) oxide) and for anhydrous or hydrated $\mathrm{Fe}_{2} \mathrm{O}_{3}$ (resp., red and yellow iron (III) oxides).

So as a starting point for calculating a TRL for nano$\mathrm{Fe}_{3} \mathrm{O}_{4}$, one may assume by inference the actual standards for $\mathrm{Fe}_{2} \mathrm{O}_{3}$, dust and/or fume which are

USA OSHA PEL-TWA $10 \mathrm{mg} / \mathrm{m}^{3}$ (as Fe); USA NIOSH REL-TWA $5 \mathrm{mg} / \mathrm{m}^{3}$ (as Fe).
Canadian OEL (occupational exposure limit)—TWA $5 \mathrm{mg} / \mathrm{m}^{3}$ for respirable dust (in Alberta) or $10 \mathrm{mg} / \mathrm{m}^{3}$ for total dust (in British Columbia).

Russian MAC (maximum allowable concentration)work shift average $6 \mathrm{mg} / \mathrm{m}^{3}$.

Note that the Russian MAC established for whole $\mathrm{Fe}_{2} \mathrm{O}_{3}$ substance is equivalent to ca. $2 \mathrm{mg} / \mathrm{m}^{3}$, if recalculated for $\mathrm{Fe}$, and so is really the most conservative. Taking into consideration the precautionary principle, we propose to start just from this MAC and then to diminish it in accordance with the above-mentioned Australian suggestion as the most conservative too.

Thus, we believe worth consideration our proposal of the TRL for engineered magnetite particles of any nanoscale dimension at a level no higher than $0.066 * 6=\sim 0.4 \mathrm{mg} / \mathrm{m}^{3}$ (as TWA). This value is close enough to the above-mentioned NIOSH REL for ultrafine $\mathrm{TiO}_{2}\left(0.3 \mathrm{mg} / \mathrm{m}^{3}\right)$.

It should be stipulated that in Russia, we have two kinds of air contamination standards (each of them separately for workroom and for ambient air) called the maximum allowable concentrations (MAC, in Russian-PDK) and tentatively safe exposure levels (TSEL, in Russian-OBUV). Unlike the NIOSH REL (as opposite to the OSHA PEL), the TSEL is not a recommended but a no less legally enforceable value than MAC, although deemed to be less reliably substantiated as compared with the latter and therefore subject to reevaluation in future. One should keep in mind also that even one and the same abbreviated term REL means not quite the same in one and the same country (USA) depending on who uses it: "Recommended Exposure Limit" of the NIOSH, or "Reference Exposure Level" of the Cal-EPA (OEHHA). We do not want to tie our proposals unambiguously to definite regulatory practices of this or that country or agency (whose practices seem to differ rather in technicalities than in principle) and so prefer to evade using any of these officially accepted terms. That is why, in the context of this paper, we deliberately use a substitute neutral term "tentative reference level."

\section{Conclusion}

The results obtained in our studies are in accordance with the prevailing views that a substance, even when relatively innocuous in bulk or as a microscale particulate, may be markedly toxic in the form of nanoparticles. However, within the conventional nanometer range, the dependence of toxicity on particle size is intricate and non-unique due to complex and often contradirectional relationships between the intrinsic biological aggressiveness of the specific nanoparticles, on the one hand, and complex mechanisms that control their biokinetics, on the other. At the same time, our results permit us to maintain that the widespread concept of quasi-defenselessness of organism against nanoparticles should be critically re-evaluated.

Therefore, we believe that (a) a safe level of human exposure to nanoparticles is possible in principle; (b) there may be no reliable foundations for establishing different safe exposure levels for nanoparticles of different size; (c) for some specific nanomaterials which are satisfactorily 
characterized already by toxicological research comparing them with their micrometer counterparts, such levels can be proposed at this stage, even if tentatively, based on sufficiently conservative approach of decreasing by approximately one order of magnitude exposure limits established or recommended for respective micro-scale industrial aerosols. There is no doubt, however, that more sophisticated study of the same nanomaterials' adverse effects (their possible carcinogenicity included) and of dose-response relationships, as well as further discussion on the general ideology and methodology of substantiating reference exposure levels for nanomaterials are necessary.

Based on these general premises, we propose for consideration a tentative reference level for engineered iron oxide nanoparticles in workroom air equal to $0.4 \mathrm{mg} / \mathrm{m}^{3}$ (as TWA).

\section{Abbreviations}

NP: Nanoparticle

BALF: Bronchoalveolar lavage fluid

AM: Alveolar macrophage

NL: $\quad$ Neutrophile leukocyte

sc-AFM: Semicontact atomic force microscopy

TEM: Transmission electron microscopy

TRL: $\quad$ Tentative reference level.

\section{Conflicts of Interests}

The authors declared no conflict of interests with respect to designing this study, conducting it, and the authorship or publication of this paper.

\section{Acknowledgments}

The authors are sincerely grateful to late T. D. Degtyareva, and O. S. Yeremenko, (from the Ekaterinburg (Medical Research Centre for Prophylaxis and Health Protection in Industrial Workers), M. Ya. Khodos, A. N. Kozitsina, N. A. Malakhova, Yu. A. Glazyrina (from the Ural State University of Economics), V. Ya. Shur, E. V. Nikolaeva, V. A. Vazhenin, A. P. Potapov, M. V. Morozova (from the Ural State University), I. E. Valamina (from the Ural State Medical Academy), L. G. Tulakina, S. V. Pichugova, and J. B. Beikin (from the Ekaterinburg City Clinical Diagnostics Centre) who contributed to carrying out different investigations summarized by the authors and coauthored respective primary publications referred to in this paper. The research was carried out thanks to the funding from the part of the Russian Federal Ministry of Education and Science.

\section{References}

[1] K. Donaldson, V. Stone, C. L. Tran, W. Kreyling, and P. J. A. Borm, "Nanotoxicology," Occupational and Environmental Medicine, vol. 61, no. 9, pp. 727-728, 2004.

[2] G. Oberdörster, E. Oberdörster, and J. Oberdörster, "Nanotoxicology: an emerging discipline evolving from studies of ultrafine particles," Environmental Health Perspectives, vol. 113, no. 7, pp. 823-839, 2005.
[3] N. G. Bastús, E. Casals, S. Vázquez-Campos, and V. Puntes, "Reactivity of engineered inorganic nanoparticles and carbon nanostructures in biological media," Nanotoxicology, vol. 2, no. 3, pp. 99-112, 2008.

[4] N. Li, T. Xia, and A. E. Nel, "The role of oxidative stress in ambient particulate matter-induced lung diseases and its implications in the toxicity of engineered nanoparticles," Free Radical Biology and Medicine, vol. 44, no. 9, pp. 1689-1699, 2008.

[5] D. B. Warheit, K. L. Reed, and C. M. Sayes, "A role for surface reactivity in $\mathrm{TiO}_{2}$ and quartz-related nanoparticle pulmonary toxicity," Nanotoxicology, vol. 3, no. 3, pp. 181-187, 2009.

[6] D. B. Warheit, T. R. Webb, V. L. Colvin, K. L. Reed, and C. M. Sayes, "Pulmonary bioassay studies with nanoscale and finequartz particles in rats: toxicity is not dependent upon particle size but on surface characteristics," Toxicological Sciences, vol. 95, no. 1, pp. 270-280, 2007.

[7] H. L. Karlsson, J. Gustafsson, P. Cronholm, and L. Möller, "Size-dependent toxicity of metal oxide particles-A comparison between nano- and micrometer size," Toxicology Letters, vol. 188, no. 2, pp. 112-118, 2009.

[8] R. A. Yokel and R. C. MacPhail, "Engineered nanomaterials: exposures, hazards, and risk prevention," Journal of Occupational Medicine and Toxicology, vol. 6, no. 1, article 7, 2011.

[9] V. Murashov, P. Schulte, C. Geraci, and J. Howard, "Regulatory approaches to worker protection in nanotechnology industry in the USA and European union," Industrial Health, vol. 49, no. 3, pp. 280-296, 2011.

[10] A. Groso, A. Petri-Fink, A. Magrez, M. Riediker, and T. Meyer, "Management of nanomaterials safety in research environment," Particle and Fibre Toxicology, vol. 7, Article ID 40, 2010.

[11] P. van Broekhuizen, "Dealing with uncertainties in the nanotech workplace practice: making the precautionary approach operational," Journal of Biomedical Nanotechnology, vol. 7, no. 1, pp. 15-17, 2011.

[12] B. A. Katsnelson and L. I. Privalova, "Recruitment of phagocytizing cells into the respiratory tract as a response to the cytotoxic action of deposited particles," Environmental Health Perspectives, vol. 55, pp. 313-325, 1984.

[13] L. I. Privalova, B. A. Katsnelson, and A. B. Osipenko, "Response of a phagocyte cell system to products of macrophage breakdown as a probable mechanism of alveolar phagocytosis adaptation to deposition of particles of different cytotoxicity," Environmental Health Perspectives, vol. 35, pp. 205-218, 1980.

[14] L. I. Privalova, B. A. Katsnelson, and L. N. Yelnichnykh, "Some peculiarities of the pulmonary phagocytotic response: dust retention kinetics and silicosis development during long term exposure of rats to high quartz dust levels," British Journal of Industrial Medicine, vol. 44, no. 4, pp. 228-235, 1987.

[15] L. I. Privalova, B. A. Katsnelson, N. Y. Sharapova, and N. S. Kislitsina, "On the relationship between activation and breakdown of macrophages in the pathogenesis of silicosis (An overview)," Medicina del Lavoro, vol. 86, no. 6, pp. 511-521, 1995.

[16] B. A. Katsnelson, L. K. Konyscheva, N. Y. Sharapova, and L. I. Privalova, "Prediction of the comparative intensity of pneumoconiotic changes caused by chronic inhalation exposure to dusts of different cytotoxicity by means of a mathematical model," Occupational and Environmental Medicine, vol. 51, no. 3, pp. 173-180, 1994.

[17] B. A. Katsnelson, O. G. Alekseyeva, L. I. Privalova, and E. V. Polzik, Pneumoconioses: The Pathogenesis and Biological 
Prophylaxis, The Urals Division of the RAS, Ekaterinburg, Russia, 1995.

[18] B. A. Katsnelson, L. K. Konysheva, L. I. Privalova, and N. Y. Sharapova, "Quartz dust retention in rat lungs under chronic exposure simulated by a multicompartmental model: further evidence of the key role of the cytotoxicity of quartz particles," Inhalation Toxicology, vol. 9, no. 8, pp. 703-715, 1997.

[19] B. Katsnelson, L. I. Privalova, S. V. Kuzmin et al., "Some peculiarities of pulmonary clearance mechanisms in rats after intratracheal instillation of magnetite $\left(\mathrm{Fe}_{3} \mathrm{O}_{4}\right)$ suspensions with different particle sizes in the nanometer and micrometer ranges: are we defenseless against nanoparticles?" International Journal of Occupational and Environmental Health, vol. 16, no. 4, pp. 508-524, 2010.

[20] K. H. Kilburn, "Alveolar clearance of particles. A bullfrog lung model," Archives of Environmental Health, vol. 18, no. 4, pp. 556-563, 1969.

[21] B. A. Katsnelson, T. D. Degtyareva, I. I. Minigalieva et al., "Subchronic systemic toxicity and bioaccumulation of $\mathrm{Fe}_{3} \mathrm{O}_{4}$ nano- and microparticles following repeated intraperitoneal administration to rats," International Journal of Toxicology, vol. 30, no. 1, pp. 59-68, 2011.

[22] B. A. Katsnelson, L. I. Privalova, M. P. Sutunkova et al., "The "in vivo" interaction between iron oxide $\mathrm{Fe}_{3} \mathrm{O}_{4}$ nanoparticles and alveolar macrophages," Bulletin of Experimental Biology and Medicine, vol. 152, no. 5, pp. 627-631, 2012.

[23] B. A. Katsnelson, L. I. Privalova, and M. P. Sutunkova, "Uptake of some metallic nanoparticles by, and their impact on pulmonary macrophages in vivo as viewed by optical, atomic force, and transmission electron microscopy," Journal of Nanomedicine \& Nanotechnology, vol. 3, no. 1, pp. 1-8, 2012.

[24] L. M. Petin, "Establishment of the maximum permissible concentrations of silica-containing condensation aerosols," Meditsina Truda I Promyshlennaya Ekologiya, no. 6, pp. 28-33, 1978.

[25] E. Ying and H. M. Hwang, "In vitro evaluation of the cytotoxicity of iron oxide nanoparticles with different coatings and different sizes in A3 human T lymphocytes," Science of the Total Environment, vol. 408, no. 20, pp. 4475-4481, 2010.

[26] A. C. Allison, "Lysosomes and the toxicity of particulate pollutants," Archives of Internal Medicine, vol. 128, no. 1, pp. 131-139, 1971.

[27] K. Tsuchiya, N. Nitta, A. Sonoda et al., "Histological study of the biodynamics of iron oxide nanoparticles with different diameters," International Journal of Nanomedicine, vol. 6, pp. 1587-1594, 2011.

[28] CDC and NIOSH, Current Intelligence Bulletin 63: Occupational Exposure to Titanium Dioxide, US Department of Health and Human Services, NIOSH, 2011.

[29] Safe Work Australia, Engineered Nanomaterials: Feasibility of establishing exposure standards and using control banding in Australia, 2010. 

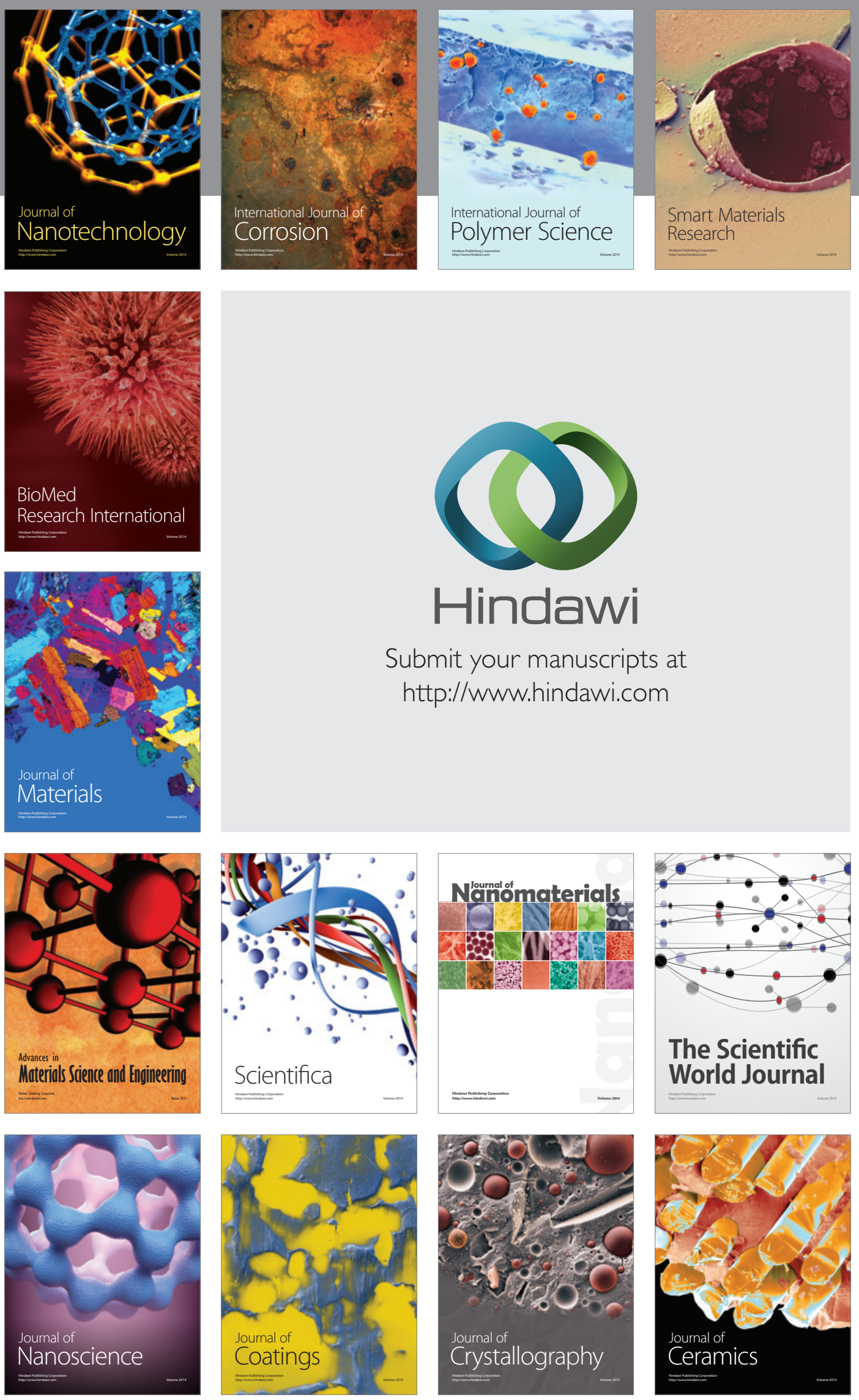

The Scientific World Journal

Submit your manuscripts at

http://www.hindawi.com

\section{World Journal}

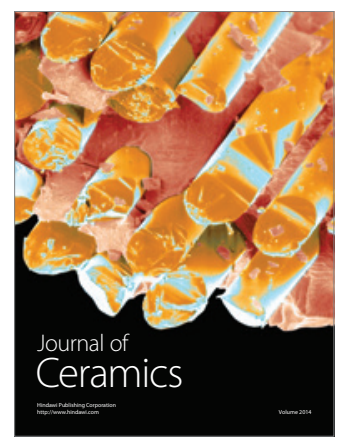

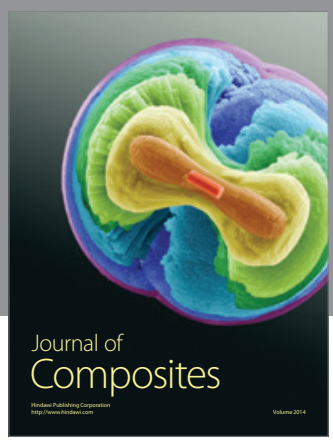
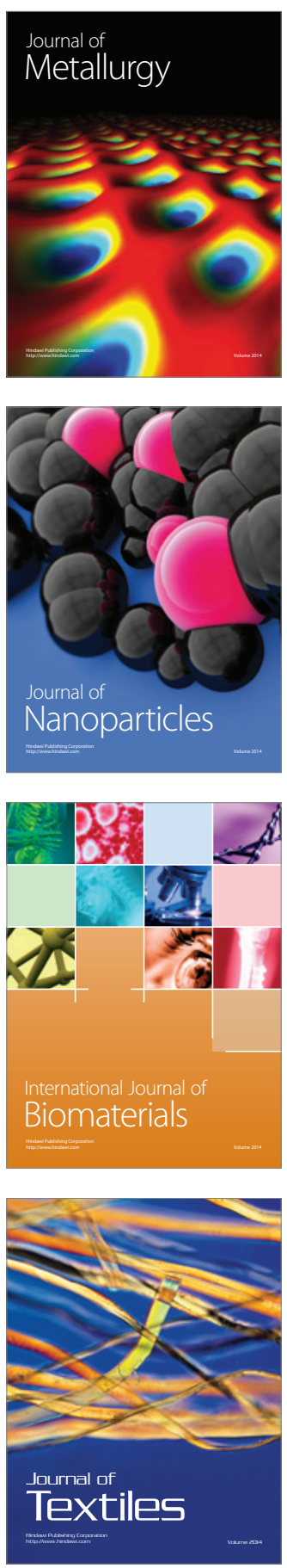